Bond University

Research Repository

\title{
Affect Mirrors
}

\section{Cox, Damian}

\section{Published in:}

Intercultural Mirrors: Dynamic Reconstruction of Identity

DOI:

10.1163/9789004401303_010

\section{Licence:}

Other

Link to output in Bond University research repository.

Recommended citation(APA):

Cox, D. (2019). Affect Mirrors. In M-C. Patron, \& J. Kraven (Eds.), Intercultural Mirrors: Dynamic Reconstruction of Identity (pp. 186-199). Brill. https://doi.org/10.1163/9789004401303_010

\section{General rights}

Copyright and moral rights for the publications made accessible in the public portal are retained by the authors and/or other copyright owners and it is a condition of accessing publications that users recognise and abide by the legal requirements associated with these rights.

For more information, or if you believe that this document breaches copyright, please contact the Bond University research repository coordinator. 


\section{Affect Mirrors}

Damian Cox

Identity and Affect

The experience of identity is not just a matter of registering the facts of one's identity: that one is a person of a particular culture, religion, class, gender, sexuality, moral character, and so on. It is also a matter of one's affective dispositions. To experience oneself as having a certain identity is feel in certain ways: about oneself and about the sense of belonging or estrangement one feels in one's social environment or cultural milieu, about the comfort, joy, envy, tension, or shared emotion one experiences with loved ones, relations, colleagues and acquaintances. The lived experience of identity is a complex mix of affect and intellect.

Identity is also intersectionally complex. One may identify as a member of a particular culture, but also as a minority in tension with that culture, as someone whose gender-choices, sexuality, moral personality, religious convictions, aesthetic preferences, political values, family structure and personal commitments intersect in complex ways with one's dominant culture. This complexity has profound effects on how one experiences life, including, of course, the affects, moods, and emotions which lend shape and texture to experience.

Because of this intersectional complexity, the experience of identity is a subtle and challenging epistemic matter. We face a never completed struggle to understand ourselves. Our epistemic condition becomes more perilous still when we seek self-understanding in intercultural settings, where a tacit background of cultural fixed points - the things we greedily take for granted in monocultures - become fluid and questionable.

This paper is about affective self-understanding in intercultural encounters, encounters in which our cultural presuppositions come into question. It is about how intercultural encounters can help us to understand ourselves better, not just our beliefs and assumptions, but also our emotions 
and our moods and what they mean to us. My key claim is that emotional self-understanding can emerge from what I call affect mirrors. In an affect mirror, we come to understand our own affect by seeing it mirrored in another. My first task is to develop a conceptual map of this phenomenon, carefully distinguishing it from other ways in which we emotionally interact with others. My second task is to illustrate affect mirrors in action. I do this through analysis of two works of cinema: Call Me by Your Name (Guadagnino, 2017) and La Promesse (Jean-Pierre and Luc Dardenne, 1996). Call Me by Your Name illustrates the phenomena in a largely shared cultural milieu. I use it to set up a contrast with the more ethically profound effect produced by affect mirrors in the intercultural encounter at the heart of La Promesse.

I do not claim that affect mirrors are the only, or even most significant, way in which selfknowledge emerges through intercultural encounters. There are many other ways - more explicitly cognitive ways - in which intercultural encounters generate self-knowledge. Knowledge of our own character, cultural specificity, and beliefs can grow by seeing how someone who does not share our culture responds to us - someone who does not frame things exactly as we do, who does not assume the things we assume or interpret events quite in the way we do, and who does not experience events in quite the way we do. One can "see oneself in the eyes of another" or one gain perspective on oneself by evident contrast with others who are culturally different. Nonetheless, my focus in this paper is on affect mirrors. The aim is to excavate the epistemic power of mirroring as it illuminates emotional self-knowledge. Emotional self-knowledge is the most elusive and subtle of phenomena. And it requires careful, circumspect, conceptual inquiry.

\section{Emotional Self-Knowledge}

This part of the paper is a philosophical inquiry into emotional self-knowledge. More specifically, it is an inquiry into the possibility of understanding one's own emotions as one experiences them. I concentrate on occurrent emotional self-knowledge because it is the fundamental phenomenon 
here. Our powers of reflective self-knowledge - knowledge of our emotional experience after the fact, generated by reflection on the character, background and significance of past affect - is built from occurrent emotional self-knowledge and extends the conceptual and interpretative tools already employed in occurrent self-knowledge. Occurrent self-knowledge is thus the best place to start our philosophical inquiry.

We need to start out from a robust, reasonably ecumenical account of emotion. My choice is something I call the construal theory of emotion. According to construal theory, emotions are interpretations of interoceptive feeling. (Interoceptive feelings are felt representations of the state of the body: whether calm, upset, in pain, unbalanced, and so on.) In emotional experience, we feel a certain way and conceptualise, interpret, or construe this feeling as having a certain meaning. We don't just have interoceptive feelings, we construe them. In this way, emotions are a fundamentally hermeneutic phenomenon. A construal of an interoceptive feeling is an interpretation of that feeling, and will often involve appraisal of situations. ${ }^{i i}$ For example, I may interpret my feeling of upset as a response to my being ill-treated. This construal of my feeling constitutes my being angry. Construals can be explicit or implicit. They can be hidden or disguised from ourselves, and they can be repressed. More typically, they are constituents of consciousness: primarily of our conscious selfapprehension. We experience ourselves and our predicaments through our emotions.

To know one's own emotions as one experiences them can be a difficult thing. This is especially clear on the construal account of emotion. To know that I feel angry, for example, is to know that I am construing my agitated and unpleasant interoceptive state in a particular way: that I am drawing it into a conceptual net of instances in which I regard myself, or some other with whom I am psychologically aligned, to have been wronged or ill-treated. To know that I am angry (as opposed to frustrated, disappointed, despairing, resentful, anxious, bitter...) is to know that I am making such a construal: not just that I believe myself to have been ill-treated, but that my illtreatment constitutes the terms in which I construe my affective state. Such knowledge requires me 
to represent to myself, not just what my affective states are in broad-brushstroke terms, but also how I am interpreting these states.

Here is one problem with the idea of emotional self-knowledge. To explicitly represent to myself how I am interpreting my affective state is often to re-interpret that state. Imagine a case in which I advance a proposal at a meeting only to have the idea shot down in flames by a friend. Imagine that my proposal is consequently dismissed out of hand at the meeting. I become agitated and upset. I ask myself whether I am I angry at my (erstwhile?) friend. Am I angry at myself (for doing such a shoddy job of advocating for my proposal)? Am I merely disappointed? Am I embarrassed and hiding my embarrassment under the cover of a pretended anger? Am I bitter about the way these meetings go - at yet another instance of the short-sightedness and selfishness of my colleagues, even those I regard as friends? Am I all these things at once? Am I none of them in particular? The task of answering these questions may well be, at the same time, a process of determining the meaning or significance of my feelings. In such a case, I would not be discovering my emotional state so much as either determining or redefining what that state is.

Am I angry with my friend? To answer this question, I must work out whether I regard my friend as having wronged me and whether I construe my feelings in the light of this. To be angry is not just to be upset and at the same time recognise that I have been wronged, it is to be upset that I have been wronged. But just asking the question can - often will - sort out attitudes that are not yet fully formed or change attitudes that are only feebly set in place. I answer it, typically, by reviewing the grounds for thinking I have been wronged. In the moment, in the grip of the feeling, I am likely to ask, not "do I regard my friend as having wronged me?" but "has my friend wronged me?" Perhaps I am pretending to myself that they have wronged me, and am indulging in feelings of anger, directed outwards, rather than the more painful feelings of embarrassment and self-reproach, directed inwards. To know my emotions is to know the answer to a question such as this. Of course, pretence is hard to maintain in the face of such knowledge. The task of acquiring knowledge of one's 
emotions is liable to disrupt and alter them; to interrogate the interpretations of one's feelings is, often, at the same time, to re-interpret them and thus to re-constitute the emotional experience itself.

Often, then, in the midst of an emotional experience, the attempt to understand one's emotions is transformative or determinative, rather than exploratory. This isn't inevitable. If the story is straightforward, if I am upset, know that I regard myself as having been wronged, and maintain that sense on reflection, then the experience is not significantly transformed under reflection. I am angry and I know it. My point is simply that emotional experience can be, and often is, transformed under reflection.

I have mentioned three ways this happens. First, an indeterminate emotional experience may become determinate under reflection. I ask myself whether I am angry or disappointed; I decide that I am disappointed; and the character of my experience changes. It wasn't that I was angry and have talked myself out of it. It is that I wasn't determinately anything until I reflected upon my affect and its significance. I am upset but the meaning of the upset is not settled, and on reflection I settle upon a construal of my feelings which becomes my emotion. This is emotional self-knowledge as self-determination of emotion. The second way emotional self-knowledge alters emotion occurs when a fragile construal is altered by reflection. I am angry but that construal collapses on reflection - I come to realise that I have not been wronged - and my emotional experience is transformed. In the third kind of scenario a pretence is undone. I am angry because that is the least painful way of construing my feelings, but reflection exposes my pretence and the emotional experience is transformed as a result. My anger may not disappear because its ground has been refuted or its basis in pretence exposed. When emotions persist in this way, they persist because our interoceptive feelings persist and we have the capacity to sustain a self-deceptive construal of them. I realise that my anger is a pretence, but immediately distract myself from the insight and focus my attention on a suitable cover story. I re-confirm the original construal, but now in a wilfully self- 
deceptive mode. Self-deceptively re-affirmed emotion is not, I think, quite the same experience as emotion based on unchallenged pretence, so even here reflection transforms emotional experience.

\section{Affect Mirrors}

With this basic picture of the transformative and determinative possibilities of emotional selfreflection in place, let me turn my attention to the idea of mirroring. What I call an affect mirror is a way of learning about one's own emotional state by seeing a form of it mirrored in another person. This is far from the only way in which interaction with others enhances emotional self-understanding or emotional lucidity, but it is a crucial way and I concentrate on it here.

First, it is important to distinguish affect mirroring from both empathy and emotional contagion. The term "emotional contagion" describes situations in which two or more people come to share similar emotions without the existence of a common cause explanation of the sharing. For example, a person joining a happy, smiling group may experience elevated levels of happiness without a shared cause of happiness. Most psychological studies of emotional contagion focus on primitive forms of this phenomenon. According to Hatfield, Cacioppo and Rapson, primitive emotional contagion refers to the way in which groups converge emotionally because they tend to copy each other's facial expressions, postures, vocalizations.iii It is supposed to be largely automatic, unintentional and unreflective. Someone experiencing primitive emotional contagion isn't given insight into their true inner happiness, or anything of the sort, they are made happier by the presence of others exhibiting happiness.

Empathy is a related but distinct phenomenon. In an empathetic reaction one mirrors, to a degree, the emotion of another, but with an accessible common cause. I empathise with the sadness of another when I both share something of their sadness and appreciate its ground. Framed in terms of construal theory, the interpretation of my interoceptive feeling is aligned (though not identical) 
with the interpretation of the other's interoceptive feeling. In empathy we share a meaningful encounter; I am not just sad because you are sad, I am sad because I understand your sadness and interpret my feelings in the light of this understanding. In emotional contagion, the meanings of shared emotions are unaligned (or only accidentally aligned). When joining the happy group, I am happy; but what I am happy about, if anything, is likely to be quite distinct from what others are happy about. iv

I am concerned with how we may come to understand our own emotions better by interacting with others, not how we might catch emotions from them. So, it is important to rule out cases of empathy and emotional contagion from the start. It is also important, I think, to navigate between the following false dichotomy. When I understand the emotion of another, I can either come to share the emotion (as in empathy and emotional contagion) or discover the same emotion already formed in myself. In the latter case, I come to know my own emotional state by seeing that very state reflected in another and, thus prompted, come to recognise it in myself. No doubt, both things happen, and often, but there is another possibility. In coming to see an emotional state of another, I may be prompted to construe my own interoceptive feelings in line with it. This construal may be new to me, or a refined or varied version of a construal already in place, but it is at the same time an apt construal: one that integrates well into the history of my feelings and their variations, the varied judgements and appraisals that attend them, and other features of my economy of affect and desire. The newly minted interpretations of my affects are fitting in this sense. They don't show me the emotion I was experiencing all along. They show me the interpretation of feeling that I should have been making all along. They make clear to me the most lucid and true meaning of my feelings. In this way, they generate emotional self-knowledge, but also a transformed emotional experience.

If I am right about this, emotional self-knowledge is gained in affect mirroring, but not always or necessarily by holding a mirror up to emotional states already fully formed in ourselves. 
Between recognition ("Your sadness has made me realise that I am sad in just the same way!") and contagion ("Your sadness has brought me low.") lies what I will call fitting reconstrual ("Your sadness has made me realise how I haven't been allowing myself to feel a sadness that is entirely apt for me; in a sense, I should be feeling sad.") One way to express this point is to say that emotional lucidity is produced not merely by the discovery of extant emotions, but by the fitting re-construal and thus transformation of our emotions through experience and reflection.

Affect mirrors as fitting reconstruals of affect is the phenomenon I wish to draw attention to. It parallels the ways in which self-reflection not only reveals what is already present, but transforms and determines what is already present. Other-reflection - mirroring of affect - not only reveals what is already present, but what might have been present given more lucid and insightful interpretation of affect. Others can show us, not only what our emotions are, but what they, in some sense, ought to be.

\section{Call Me by Your Name}

I examine two examples of affect mirrors working in this way. They both come from films: Call Me by Your Name (Guadagnino, 2017) and La Promesse (Jean-Pierre and Luc Dardenne, 1996). In this section, I discuss Call Me by Your Name. It is a story of a love affair between Elio and Oliver. Oliver is visiting Elio's family in Northern Italy for the summer; Oliver is a young philosopher completing a manuscript of Heraclitus. Elio becomes obsessed with Oliver and encounters an infuriating mix of attentiveness, indifference and distain from him. In the central revelation scene (46 minutes into the film) - when Elio, obliquely but unmistakably, declares his passion for Oliver - Oliver is forced to reconstrue his own feelings. I think the best interpretation of the scene is that Oliver comes to emotional lucidity through an affect mirror. In Elio's longing he sees his own; his affects - the restlessness and sexual frustration; the instability of pleasure and fear in Elio's company - are reconstrued as an undisguised erotic longing for Elio. In this scene - it is a prelude to Elio's seduction 
of Oliver - affect mirroring comes from a recognition that the couples' feelings must be interpreted together. When Elio's longing for Olivier is made patent to Oliver, Oliver does appear to reflect back a longing that was fully formed and fully experienced, but rather reflects back a longing that now fits properly with his orectic economy. ${ }^{\vee}$ Emotional lucidity isn't necessarily a matter of discovering what was already there - intact and fully made - but of transforming the inchoate beginnings of emotion to into what makes sense.

The power of affect mirrors explains the erotic character of a game Elio and Oliver play, one which gives the film (and the novel on which it is based) its title. At 1 hour, 25 minutes into the film, Oliver has Elio call him by his own name: Elio calls Oliver "Elio", and Oliver calls Elio "Oliver". This might seem like a narcissistic affair - as if the true love object of each man is himself - but I don't think this is the case. It is, I think, best understood as an intensification of affect mirroring. Calling one's lover by one's own name, and being called your lover's name, takes the longing and desire one sees in the other and mirrors it inward. The desire of the other is treated as if it were one's own desire; and one's own desire is treated as if it were the other's. It is as if two desire mirrors are held up to each other. This orectic interpretation makes better sense, I think, than a simple identity-based interpretation. Elio and Oliver are not seeking to meld their identities. There isn't enough cognitive depth to the game to support such a thing.

Affect mirroring has a clear role to play in respectful and valuable erotic encounters, and Call Me by Your Name illustrates this convincingly. Nonetheless, the encounter between Oliver and Elio is far from an intercultural one. They are both Jewish Americans. Oliver is an academic; Elio, a musically gifted, precocious, scholarly teenager, is the son of an academic. The film is set in Northern Italy, in 1983, on an estate which is the summer residence of Elio's family. Elio is at home, Oliver is a visitor. The principle difference between them is age. Elio is 17 and Oliver 24; this is a relationship between a teenager and an adult. (The film exaggerates the difference because the actor playing Oliver, Armie Hammer, was 31 at the time of filming and looked it; the actor playing Elio, Timothee 
Chalamet, though 21 at the time of filming, looked, if anything, younger than 17.) This age difference makes Oliver's passivity in the face of Elio's attentions plainly understandable. Oliver's passivity and his initial refusal to allow Elio to get close to him need to be overcome for the relationship between them to begin. Affect mirroring generates this overcoming. Seeing one's own affective state mirrored in another, a bridge is created, and the possibility of erotic and emotional closeness opens up. Epistemically, affect mirroring opens up for Oliver the possibility of not only understanding the affects of the other, but of understanding his own affects and their apt construal.

\section{La Promesse}

Affect mirrors play a crucial role in La Promesse, though in a very different way. In La Promesse, the chief encounter is between the teenage Igor and a women from Burkina Faso, Assita. The films are very different works of art. Whereas Call Me by Your Name is a seductive and conventionally attractive film (attractive protagonists; beautiful settings; a visually, aurally, musically rich evocation of languid summer days), La Promesse is austere and gripping. What is remarkable about the Dardenne brothers' film, as with their cinema in general, is its exploration of the possibility and the beauty of moral goodness and redemption. It does this with considerable rigor and an absence of sentimentality. Watching the film is a deeply involving experience once you accustom yourself to its austere style. Strong currents of feeling are revealed, but only through the most direct means: by watching characters do things and say things, observing the expression on their faces and in their bodies as they work. A complete absence of background music and tightly framed, mostly hand-held camera work gives the superficial impression of a documentary style, but every scene is carefully organized. The power of the Dardenne brothers' technique lies in its capacity to focus the viewer's attention on the way the characters live in their environment; not how they operate in a fictional setting, but how they live in a seemingly real environment. The settings are messy, unlovely, inconvenient and the action appears to be unstaged. We follow characters up stairs and through doorways, into cars, along the 
street; sometimes from behind, or the side, or the front. It is like observing action as an accidental bystander rather than having a scene staged for us. Unlike conventional filmic setups (mise-en-scène), where the aim is to optimize the communication of narrative information - What is happening? Who is talking to whom? What are these people feeling? What are their motives? What kind of people are they? - the Dardenne brothers' technique aims to show characters' action as if nothing is staged; as if the filmmakers have happened upon it. Narrative information seems to emerge non-deliberately. ${ }^{\text {vi }}$ La promesse's narrative progression seems almost accidental; as if one scene could easily be substituted for many other scenes. In fact, however, every scene is designed to make a special point about the life and troubles of the main character, Igor, and could not easily be substituted with other scenes.

Igor's troubles are very real. He is a 15 years old apprentice motor mechanic whose real job appears to be to aid his father, Roger, in various odious criminal activities. (Indeed Igor is soon fired from his job as apprentice mechanic.) We first see Igor steal a purse from a customer, but much worse is soon to follow. He helps his father run a kind of hostel for undocumented arrivals to Belgium (people who face deportation if discovered by Belgian immigration officials). These people come from various places - including Yugoslavia, Korea and, crucially, the West African nation of Burkina Faso. Roger extorts cash and cheap-labour from them. He also seems to run, or at least profit from, the people-smuggling operation that brings the undocumented migrants into Belgium in the first place. To get immigration officials off his back, Roger also sets up some of his hostel residents for arrest and deportation and enlists Igor's help in the operation. Roger is building a house - for his son, he tells us at the very end of the film - and the worksite is a disorganized and unsafe mess. The work is dangerous and safety precautions are ignored. During a sweep by labourinspectors, while everybody else rushes to hide, one worker falls from scaffolding. (He has no safety harness.) This is Hamidu, a man from Burkino Faso whose wife (Assita) and child who have just joined him in Belgium. As he lies seriously injured, Hamidu gets Igor to promise to look after Assita and the child. Igor's immediate actions, however, are to hide the injured man and then help his 
father lie to the inspectors. After the inspectors leave, Igor tries to get Hamidu taken to hospital, but his father will not hear of it. Under orders, Igor helps his father hide Hamidu under a plastic tarpaulin and a slab of wood (a detached, wooden door); they cover traces of his blood with sand. At some point in the day Hamidu dies. That night, Roger and Igor bury his body in the building site.

This is the basic set-up. The film focuses on Igor's gradual response to the moral calamity of Hamidu's death and the culpability he shares with his father (though, of course, it is mostly owned by his father). In one way, Igor's response is quite simple. He makes good on his promise to Hamidu. But this way of putting things does little service to the subtlety of the film's portrayal of Igor's moral awakening. This awakening is the philosophical heart of the film. Igor responds to a promise: the promise of a dying man. Igor establishes a clear moral identity in the film, but how should we describe this identity? What sort of person has he become? The key aspect of this transformation is integrity. What Igor acquires in the course of the narrative is moral integrity. This integrity consists, not just in a robust willingness to honour promises even when it is very difficult to do so. It consists in a capacity to recognise what is required of one, given what one has done, given who one is in relationship with, given the circumstances of that relationship. Integrity isn't just a determination to act on principle, and the courage and tenacity to see the determination through when it is dangerous, onerous and difficult. It is the capacity to see - in context - what is required of one; it is a capacity to understand what one must do to remain true to the best version of oneself. Igor comes to realise this at the very conclusion of the film.

Accompanying Assita to oracle ceremony seeking to determine her husband's fate, Igor comes to realise how important the discovery of the resting place of her husband is to Assita (1 hour, 11 minutes). It is a fundamental cultural need. Igor has been helping Assita under the pretence that her husband is still alive but has run away to escape gambling debts. This is Roger's lie. Igor arranges for Assita to journey to Italy to an uncle, something that will get her out of harm's way (Roger's harm). In the final scene of the film, as Assita and her child are about the board the train to Italy, Igor tells her 
the truth about the death of her husband and his on role in it. He does so in a few, succinct, unadorned, sentences. (The scene takes place at 1 hour, 27 minutes into the film.) Assita reacts by removing her headscarf, slowly turning from the station platform, looking at lgor: sadly, severely. She walks out of the station; Igor accompanies her. We watch them walking away together until they disappear from view. The final scene is a small, but also profound, moral victory for Igor.

The film is about the moral transformation of its protagonist, Igor. Although Assita is fundamentally important character in the film and the source of Igor's transformative experience, it is not her film. It is a film very much stuck in the perspective of a western boy's encounter with an exotic and challenging stranger from an alien culture. Igor honours a promise to her dying husband; but the key to Igor's moral transformation from petty thief to a person of integrity is his emotional encounter with Assita. As he begins helping Assita, making good on his promise, Igor pays closer and closer attention to her. Her distress at the unexplained absence of her husband is mirrored by his own distress. A good way to understand Igor's moral progress is in terms of this mirroring. He isn't just honouring a promise, he is growing in his powers of empathy and moral understanding. What triggers this is a realisation of the depth and character of his own moral distress.

Why should a hitherto cold and manipulative child gain this kind of insight? He has no role model of any kind. His father is monstrous. Assita is both profoundly other to him and indifferent to him. The best answer is that Igor's encounter with Assita involves an affect mirroring relation. In her distress he comes to appreciate his own distress; and once in the open he cannot but understand its source (his father) and his own moral need (to escape his father's malign influence). Combined with the promise, this leads him to run away with Assita and eventually to see what it is she needs above all: to know the truth of what happened to her husband. Without the encounter with Assita and their shared distress, it is unlikely Igor would have experienced the extraordinary moral transformation portrayed in the film. 


\section{Intercultural Affect Mirrors}

I think it is very important that Igor and Assita's affect mirroring is an intercultural mirroring. As I argued above, the film is a one-sided portrait of an intercultural encounter. It is about lgor's discovery of his distress mirrored in Assita's, not vice versa. Affect mirroring is not a journey of discovery of the other; it is a journey of self-discovery. Nonetheless, it is crucial for the moral force of Igor's encounter with Assita that it be an intercultural one. Assita's cultural disposition shakes lgor out of his complacency - his adolescent moral torpor. Assita's response to the boy is challenging. It is unwelcoming and disdainful. She appears bewildered that this odd white boy should take an interest in her, should be helping her. At times she is quite hostile to him. When they first make their break from Igor's father (he has lied to Assita, telling her that she is to go to her husband when he plans to sell her into sex slavery), Assita, surprised, holds a knife to Igor's neck (57 minutes). Assita rebuffs Igor decisively when he later embraces her in a flood of tears ( 1 hour, 4 minutes). Her child becomes dangerously ill and she attacks Igor, throwing stones at him and accusing him of intentionally infecting the child (1 hour, 8 minutes). Assita's need to recover the body of her husband - if he is indeed dead - is culturally distant to Igor. He parses the situation in terms of the danger Roger poses to them both. Assita parses it in terms of the moral impossibility of abandoning a partner's body - allowing his spirit no resting place.

The encounter thus has two aspects to it: cultural difference and affective coincidence. Assita's distress gives Igor insight into his own, very different distress. But the cultural distinctness of Assita's distress allows Igor to understand, not just his own predicament, but the limits of his moral knowledge. In intercultural affect mirroring of this kind, one shares distress with another, but the differences count. Igor's moral need is to escape his father. Assita's moral need is to care her dead husband's body. Igor's integrity requires not that he answer his own moral need, but that he trust another's understanding of what is needed; that his integrity depends upon trusting the moral vision of a cultural stranger. I think this is key to the moral transformation of Igor. It is not just that the boy 
learns to care about others, but that he learns to care about the moral vision of others, even when it is mysterious to him.

Affect mirroring is, I think, a commonplace occurrence. We often use others as a guide to our own mysterious hearts. But intercultural affect mirrors contain an altogether more profound moral possibility. This is brought out by the contrast between Call Me by Your Name and La Promesse. Whereas Call Me by Your Name charts the erotic transformation of a couple - a very valuable thing, something that remains precious to both men throughout their lives - it does not describe a moral transformation of any kind. ${ }^{\text {vii }}$ The intercultural encounter between Igor and Assita, by contrast, is an occasion of deep moral transformation: a transformation that comes about because of the concatenation of affect mirroring and profound cultural difference. ${ }^{\text {viii }}$

\section{Endnotes}

\footnotetext{
${ }^{1}$ For a defence of this kind of theory, see Barrett, L. F. How Emotions are Made. New York: Harcourt, 2017, for a defence of this theory. Barrett calls her version of the theory "constructionist", which is somewhat opaque in this context.

${ }^{2}$ For this reason, construal theory is closely related to appraisal theory in cognitive psychology. See Scherer, K. R., \& Shorr, A., \& Johnstone, T. (Eds.) Appraisal processes in emotion: theory, methods, research. Canary, NC: Oxford University Press.

${ }^{3}$ See E. Hatfield, J. Cacioppo, \& R. L. Rapson, R. L. Emotional contagion. New York: Cambridge University Press, 1994.

${ }^{4}$ For a nuanced account of the distinction between emotional contagion and empathy see $P$. Goldie, The Emotions: A Philosophical Exploration. Oxford: Oxford University Press, 2000.

${ }^{5}$ The novel on which the film is based, by Andre Aciman (A. Aciman ${ }^{1}$ For a defence of this kind of theory, see Barrett, L. F. How Emotions are Made. New York: Harcourt, 2017, for a defence of this theory. Barrett calls her version of the theory "constructionist", which is somewhat opaque in this context.

${ }^{2}$ For this reason, construal theory is closely related to appraisal theory in cognitive psychology. See Scherer, Call Me by Your Name New York: Picador, 2007) presents a more straightforward picture, and has Oliver ater confess to Elio his early self-conscious attraction. In the novel, Oliver is represented as initially playing a self-consciously deceptive game with Elio, trying to stop an affair between them before it has a chance to start. The film is more interesting and ambiguous on this
} 
point. A retrospective confession of this kind is not made; and Oliver's shifting responses to Elio are more readily interpreted as confused rather than manipulative.

${ }^{6}$ For example, consider the scene of a central character's accident (at 24 minutes into the film). It is a pivotal narrative moment. The character's name is Hamidu. He is responsible for drawing the promise of the film's title from Igor. Hamidu is working on scaffolding outside a house. We follow Igor as he warns Hamidu of the imminent arrival of labor inspectors; Igor rushes away from Hamidu, moving inside and up the stairs - we follow him, as we do throughout almost the entire film - and then he hears a noise. It is just a dull thud. This is all the action associated with Hamidu's accident. The audience sees what Igor sees and hears what he hears. It's as if the filmmakers have had the bad luck to be in the wrong spot to witness the spectacle of the fall. It makes perfect sense, of course. The accident is something that happens. It isn't staged for Igor and it isn't staged for an audience either. Igor no more witnesses it than we do.

7 That the value of the summer romance between Elio and Oliver stays with them their whole lives is made explicit in Aciman's novel. The film, by contrast, leaves out the last section of the novel which describes future encounters between the men. As befitting a film, the action is almost entirley limited to a single, continuous timespan. It is a story of one summer's affair, though it concludes with a later phone call between Oliver and Elio, in the dead of winter, effectively ending their relationship. (Oliver announces that he is to be married.)

${ }^{8}$ This is not to say that intercultural encounters are the only available means of moral transformation. Indeed, the Dardenne Brother's work is replete with other ways in which this transformation can come about. My point is just that intercultural encounters are particularly powerful sources of transformation. 